\title{
Improving Patient Care Through the Identification of Patients' Social Needs at Various FQHC's in Michigan
}

\author{
Christal M. Clemens, MD, Michael E. Johansen MD, MS, Associate Editor \\ Ann Fam Med 2021;19(4):iii. https://doi.org/10.1370/afm.2725.
}

T The Annals of Family Medicine encourages readers to develop a learning community to improve health care and health through enhanced primary care. Participate by conducting a journal club. We encourage diverse participants to think critically and act on those discussions. ${ }^{1}$

\section{HOW IT WORKS}

In each issue, the Annals selects an article and provides discussion tips and questions. Post a summary of your conversation in our online discussion. (Open the article, click on the eLetters tab, and submit a comment.)

\section{CURRENT SELECTION}

Greenwood-Ericksen M, et al. Implementation of health-related social needs screening at Michigan health centers: a qualitative study. Ann Fam Med. 2021;19(4):310-317.

\section{Discussion Tips}

In order to provide optimal patient care, it's critical to address a patient's health-related social needs as well as medical needs. Federally qualified health centers (FQHCs) often lead in health screening for social needs, but there is no consensus on the best screening methodology. A study of Michigan FQHCs uses a qualitative methodology to analyze differences in patient screening at 5 practices.

\section{Discussion Questions}

- What questions does this study ask; why do these matter ${ }_{i}$ how strong is the study design for answering?

- How does this study advance beyond previous research and clinical practice on this topic?

- What is a qualitative descriptive study and what are its main goals, benefits, and weaknesses?

- Why was maximum variation sampling used to choose the FQHCs? What other similar types of sampling could have been used for this study?
- Describe snowball sampling. What are the advantages and limitations of snowball sampling?

- When is thematic analysis applicable in research studies and what are the 6 main steps?

- How is thematic saturation determined?

- To what degree can the findings be accounted for by how FQHC sites and care team participants were selected, excluded, or lost to follow-up?

- What are the main study findings?

- How comparable is the study to your clinic/hospital's screening practices? What is your judgment about the transportability of the findings?

- What contextual factors are important for interpreting the findings?

- What statewide initiatives are applicable to your clinic/hospital's screening practices?

- What are the pros and cons of using a standardized screening process in identifying patient needs?

- What are the limitations of this study?

-What are the main screening methods your clinic uses to identify patient social needs?

- Are community health workers involved?

- Are the results of screening included in the EMR?

$\circ$ What are some of the barriers to screening? How might screening be improved in your office?

- How might this study change your practice? Education? Research?

- Who are the constituencies for the findings; how might they be engaged in interpreting or using the findings?

-What are the next steps in interpreting or applying the findings?

- What researchable questions remain?

\section{References}

1. Stange KC, Miller WL, McLellan LA, et al. Annals Journal Club: it's time to get RADICAL. Ann Fam Med. 2006;4(3):196-197. https:// AnnFamMed.org/cgi/content/full/4/3/196 